\title{
EN CARNE VIVA. POLITICAS DE MUERTE EN OTTO; OR, UP WITH DEAD PEOPLE DE BRUCE LABRUCE
}

\section{In the flesh, death policies in Otto; Up with Dead People of Bruce LaBruce}

\author{
Martin De Mauro Rucovsky*; José G. Platzeck* \\ * Universidad Nacional de Córdoba - CONICET (Argentina) \\ martinadriandemauro@gmail.com; jose.platzeck@gmail.com
}

\section{Palabras clave \\ Biopolítica \\ Zombi \\ Sexualidad \\ Carne \\ Comunidad}

Keywords

Biopolitics

Zombie

Sexuality

Flesh

Community

\begin{abstract}
Resumen
El presente artículo analiza la figura del zombi presentada en la película Otto; or, Up with Dead People (Alemania-Canadá, 2008) del director Bruce LaBruce a partir de la perspectiva biopolítica y con especial interés en su funcionamiento inmunitario. Nos proponemos reflexionar a partir de este análisis sobre lo que llamamos "políticas de muerte" a la luz del zombi como monstruo biopolítico. En primer lugar, el zombi nos permite indagar sobre las formas de cualificación de la vida y el reparto de violencia sobre los cuerpos en torno a la distinción que puede leerse en la película entre carne viviente y carne consumible. En segundo lugar, es posible realizar a partir de la figura de Otto una reflexión sobre la sexualidad y las arquitecturas corporales en relación con el discurso del postporno. Por último, y en relación con lo anterior, el filme abre un espacio para problematizar las formas de pertenencia y la comunidad muerto-viviente a la luz de un cierto ethos neoliberal y su interpelación mercantil. La figuración del zombi nos permite así, a lo largo del desarrollo, iluminar espacios de agenciamiento o una determinada potencia afirmativa al interior del paradigma inmunitario y las políticas de muerte contemporáneas.
\end{abstract}

\begin{abstract}
This article analyzes the figure of the zombie featured in the film Otto; or, Up with Dead People from the director Bruce LaBruce from a biopolitical perspective and with special interest to immunitarian functioning. We propose to make an analysis about what we call "policies of death" in light of the zombie as a biopolitical monster. In the first place, zombie allow us to inquire the form of qualification of life and the distribution of violence on bodies around the distinction, that can be read in the film, between living flesh and meat. Secondly, through the figure of Otto, it is possible to consider an analysis about sexuality and the corporeal architectures in relation with post-porn discourse. Finally, and with regard to the foregoing, the film opens a space to problematize the form of belonging and the community of dead-living in light of a certain neoliberal ethos and its mercantile interpellation. Thus, the figure of zombie allows to illuminate spaces of agency or a certain affirmative power within the immunitarian paradigm and the contemporary policies of death.
\end{abstract}

De Mauro Rucovsky, M., y G. Platzeck, J. (2018). En carne viva. Políticas de muerte en Otto; or, Up with Dead People de Bruce LaBruce. Papeles del CEIC. International Journal on Collective Identity Research, vol. 2018/1, papel 191, CEIC (Centro de Estudios sobre la Identidad Colectiva), UPV/EHU Press, http://dx.doi.org/10.1387/pceic.17725 


\title{
1. INTRODUCCIÓN
}

\author{
Dedicado a Maite Amaya \\ Activista trans, feminista y piquetera \\ Córdoba 1981-2017
}

Bajo las matas/ En los pajonales/

Sobre los puentes/ En los canales/

Hay Cadáveres

Néstor Perlongher, Cadáveres ${ }^{1}$

La figura del zombi remite a un universo sensible muy determinado: es aquel cuerpo putrefacto que vuelve de la muerte y es justamente por ello que su retorno indica un desarreglo en el orden de los vivos. Más aun, su presencia errante despierta las más variadas fantasias y temores sociales. Los cadáveres caminantes puestos en escena exponen de manera hiperbólica el modo en que todo cuerpo está ya, desde siempre, habitado por su propia muerte (Embry y Lauro, 2008: 102). Al mismo tiempo, como figura monstruosa, desarregla el propio marco de inteligibilidad de lo humano, estableciendo una ruptura en la oposición estructural entre los términos vivo/muerto como valores absolutos, mediante la emergencia de un tercer término que niega ambos valores: ni vivo ni muerto. Así, tanto el cadáver -al que se refiere el fragmento del poema de Néstor Perlongher que sirve de epigrafe a estas páginascomo el zombi invaden la totalidad del espacio social: bajo las matas, en los pajonales, en el cementerio, en ningún lugar o por todos lados.

Nos proponemos revisar la singularidad del zombi entendido como una figura en el sentido que desarrolla Giorgio Agamben, es decir, como una relación paradigmática y ejemplar, un movimiento que va de una singularidad a otra singularidad y que permite poner en cuestión la oposición entre particular y universal que estructura todo procedimiento cognoscitivo (2010: 76-94). El zombi funciona en este sentido como una signatura o imagen sensible que define la inteligibilidad del conjunto y permite leer transversalmente, en este caso, las políticas de muerte contemporáneas y su imaginario sensible a la luz de la lógica inmunitaria. Esta operación de lectura comienza con

\footnotetext{
${ }^{1}$ Néstor Perlongher, fallecido en 1992, fue poeta, militante y académico argentino. Su poema "Cadáveres" es considerado un hito en la literatura argentina en tanto denuncia la violencia ejercida por la dictadura cívico-militar en ese país.
} 
una revisión de una película: Otto; or, Up with Dead People (AlemaniaCanadá, 2008) del cineasta canadiense Bruce LaBruce.

Del cementerio, del olvido, un cuerpo se levanta de su tumba, entre los escombros, comienza su periplo, caminata torpe y forzada, principio de un recorrido sin origen y sin rumbo. Sobre la añoranza de una vida pasada aún sobrevive su cuerpo herido y sangrante que da cuenta de un tiempo de quimeras. Interpretado por Jey Crisfar, Otto es presentado como un adolescente zombi con crisis de identidad que recorre Europa. El protagonista despierta en su tumba y comienza su recorrido, que lo lleva a encontrar un anuncio de trabajo como actor a cargo de la dirección de Medea Yarn en el filme Up with Dead People. Mientras dirige la película, Medea decide convertir fragmentos de la vida-zombi de su nuevo actor en un documental. Filmes dentro de un filme, la película despliega distintos registros yuxtapuestos: la propia sobrevida de Otto - hilo conductor que da inicio a la historia-, los recuerdos de su vida pasada, que va reconstruyendo a partir de las pertenencias que encuentra en su ropa, Up with Dead People, la película de Medea Yarn, que se muestra como un manifiesto político por momentos explícito y el registro documental llevado a cabo por la misma directora.

El relato filmográfico de Otto; or, Up with Dead People recurre a las convenciones y lugares comunes del género zombi para luego subvertirlas y llevarlas hacia su límite. Con una estética marcadamente punk y por momentos trash, la película de Bruce LaBruce se propone reactualizar el universo simbólico del zombi pero, al mismo tiempo, mantiene una mirada contrahegemónica al interior de la reciente narrativa gay zombi y su respectiva genealogía.

Resto de vida o potencia de la muerte, el cadáver andante de Otto circula desde la periferia del cementerio hacia el centro de la metrópolis alemana. Su cuerpo se desplaza en un umbral entre la no muerte y la sobrevida. Su vida carece de narración o bien su historia es fragmentaria, formada por restos no organizables: se trata de una biografía en descomposición.

La película de Bruce LaBruce se inscribe, como señalamos, en el vasto universo de la filmografía zombi, cuyas convenciones a la vez cita y desafía. En principio, el zombi es un cuerpo que advierte un desafío a las barreras entre la vida y la muerte: la posibilidad de pensar una resistencia a determinadas políticas de muerte o bien señalar el lugar de 
ciertas vidas suspendidas en ese umbral, vidas ya muertas aunque vivientes. Es por ello que esta figura ha despertado un especial interés en los estudios que parten de la perspectiva biopolítica. Paola Cortés Rocca advierte ya la necesidad de este cruce al referirse al zombi del folclore haitiano como un "monstruo biopolítico" (2009: 333). Esta afirmación se enfatiza en la versión moderna (que la crítica identifica con las producciones posteriores a la obra de George Romero) ${ }^{2}$ se trata de un cuerpo que implica a la vez una amenaza para el individuo, para la población (por su carácter contagioso) y para la especie (Platzeck, 2015 y 2016).

Retomaremos algunos estudios sobre esta película que dan cuenta de la originalidad y la potencia crítica que tiene para pensar las sexualidades disidentes y los modos de subjetivación contemporáneos. Consideramos que la película de Bruce LaBruce tiene, a casi diez años de su estreno, una vigencia latente que demanda una nueva mirada a la luz del recrudecimiento del neoliberalismo y los procesos de precarización, los dispositivos de subjetivación, la violencia inmunitaria y las formas de comunidad que se despliegan en este contexto. El relato plantea una serie de cuestionamientos que parecen vaticinar el avance fagocitario del mercado sobre las políticas de identidad, el pinkwashing, el homonacionalismo y la construcción de comunidades $\mathrm{LGTBIQ}^{3}$ en los últimos años que consideramos productivo analizar a la luz de los debates recientes de la perspectiva biopolítica.

El cruce entre la figura del zombi y las sexualidades disidentes es sugerente para el tipo de lectura que pretendemos. Trevor Grizzell (2014) propone leer la figura del zombi a la luz de los estudios queer, específicamente de la noción de "fracaso queer" de Judith Halberstam (2011) - una apropiación crítica y propositiva del fracaso-. En este sentido, el zombi hace fracasar, pone en cuestión, las definiciones de parentesco y de reproducción, la gestión de la vida y las retóricas de control biopolítico (Grizzell, 2014) que operan, como revés complementario, produciendo muerte.

\footnotetext{
${ }^{2}$ Ver Jeffrey J. Cohen: “Undead (A Zombie Oriented Ontology)" (2012: 408).

${ }^{3}$ La sigla LGTBIQ hace referencia a las sexualidades 'minoritarias', 'disidentes' o 'queer', campo diverso y cambiante de prácticas e identidades sexuales y de género que resisten o desplazan modelos heteronormativos o patriarcales: Lesbiana, Gay, Trans, Bisexual, Intersex y Queer. Catálogo o aglutinante en permanente transformación porque responde, precisamente, a la singularidad de los deseos y los cuerpos en un doble sentido, subjetivo y colectivo.
} 
Darren Elliott-Smith (2014a) advierte la originalidad de Otto frente a la narrativa zombi pero más específicamente al interior de la narrativa gay zombi. Otto es el zombi que falla ante la posibilidad de incorporarse a la horda y desde allí pareciera reafirmar su propia individualidad y marginación. Esta característica termina por poner en crisis la lógica binaria que caracteriza al género - "nosotros" (humanos) contra "ellos" (zombis)-, porque hace visible una doble violencia sobre Otto: la de la muchedumbre zombifóbica pero también la de la propia comunidad gay zombi (para el caso, falsa comunidad que hace de lo zombi una mera opción estética). Aparece así otro término en esta lógica, dado por la oposición entre un "nosotros" - la falsa comunidad zombi- contra otro "nosotros" - los verdaderos zombis gays a los que Otto representaría(ibídem).

Asimismo, cabe señalar que en Otto; or, Up with Dead People la figuración del zombi funciona también como un mecanismo que vuelve patente lógicas inmunitarias y políticas de muerte contemporáneas, al tiempo que ilumina espacios de agenciamiento o una determinada potencia afirmativa que funciona al interior de esas lógicas y de esas políticas.

Nuestro punto de partida, como señalamos, es la conceptualización de Michel Foucault sobre el poder como biopoder y fundamentalmente las reflexiones que, a partir de esa caracterización, reclaman la centralidad de la pregunta por las formas del hacer morir - a las que aludimos de manera general como "políticas de muerte"- y que funcionan conjunta e incluso complementariamente al poder sobre la vida. Organizaremos esta reflexión, que parte de la perspectiva bio(tanato)política -es decir, de un poder que se ejerce sobre la vida a la luz de este monstruo que plantea un desafío a la conceptualización del poder en tanto se presenta como un cuerpo a la vez vivo y muerto, o de modo inverso, muerto pero viviente-, en torno a tres zonas de reflexión: alimentación, sexualidad y comunidad.

\section{BIOPOLÍTICAS DE LA CARNE}

Signada por un recuerdo difuso, una imagen se torna recurrente en la película: la manipulación de trozos de carne. ¿Ese recuerdo está marcado por el trauma? ¿Era Otto un adepto al veganismo o acaso un carnicero? El relato fílmico resuelve estos interrogantes de manera 
fragmentaria. De cualquier modo, Otto no posee la capacidad para metabolizar y es por ello que no reproduce la cadena alimentaria antropológica o al menos logra interrumpirla, en la intermitencia de la ingesta, en el canibalismo zombi del vagabundo: bien puede alimentarse de pasturas, flores, algún conejo muerto que encuentra por su camino, un gato vivo en algún basural $y$, finalmente, carne, carne animal industrializada y vísceras humanas.

La mordedura zombi funciona en la película de Bruce LaBruce $y$, dentro de esta, además, en el filme de Medea que se presenta como un subregistro - Up with Dead People - como desintegradora de fronteras inmunitarias entre lo vivo y lo muerto, entre la carne consumible y la carne viviente o entre el cuerpo individual y el cuerpo ajeno. Aqui es posible leer un extraño vínculo que superpone capas de carne. De un lado, los trozos de carne en la escena de la película que transcurre en la carnicería. De otro, la carne humana de los cuerpos masculinos que se amontan en la orgía zombi, hacia el final de la película. De alli que Otto se encuentre, recorra y habite distintos escenarios de la muerte (desde el cementerio al matadero o desde la disco Flesh hasta el basural industrial o las ruinas de la periferia urbana). Estos territorios son, precisamente, espacios donde la muerte se presupone inmunizada, recluida y aislada de todo contacto social.

El filme de Medea recrea la presencia de Otto en aquel espacio de producción de carne que por excelencia ha sido el matadero: lugar de transición simbólica y material de los cuerpos vivientes en carne consumible. El matadero es un territorio y una zona expansiva que pone el foco en el amontonamiento de carne, cuerpos, cadáveres ${ }^{4}$. La presencia foránea y extraña del zombi frente a montañas de pollos procesados nos devuelve la mirada hacia aquella lógica inmunitaria que opera al interior de la cadena industrial de producción de carne, en tanto mecanismo que procura organizar y clasificar el orden sensible de los cuerpos, siempre mezclados y superpuestos.

La carne de los cuerpos, en tanto materia común a todos los vivientes animales, humanos, vacas, cerdos, cabras, etc.- ha expresado diferentes compuestos sociales a lo largo y lo ancho de la historia. En torno a la diferencia semántica entre las palabras inglesas meat y flesh

\footnotetext{
"Para una lectura en clave biopolítica sobre los "mataderos de la cultura" véase Giorgi (2014), en particular el capítulo 3 "La propiedad de los cuerpos: matadero y cultura".
} 
es posible historizar las formas en que se realiza la distinción biopolítica entre la carne viviente, la carne de los cuerpos a proteger, y la carne para consumir, la carne no cualificada del animal. La definición de meat, que antiguamente refería a un alimento que podía o no contener carne (parte comestible de un alimento sólido, vegetales o pasteles como green-meats o baked-meats) se convirtió en un verdadero modo de producción, fuerza de trabajo animal y de ganancia de capital (Hribal, 2014). La palabra inglesa meat no obtuvo su significado actual (carne de consumo) hasta entrado el siglo XIX, lo que marca un desplazamiento semántico entre meat y flesh signado por la aparición de la industria comercial del ganado vacuno - a ambos lados del Atlántico Norte- en el siglo XVII, por el consumo masivo de carne animal y por la posterior antropologización del sintagma flesh como rasgo distintivo de la corporalidad humana (humankind). Así, la carne viva, la carne común a todos los cuerpos (embodied life), se vio diseccionada entre fragmentos corporales -a ser deglutidos- y materia organizada - con sus respectivos órganos y jerarquías-. En otros términos, la carne abandonó paulatinamente su carácter corporal común para ingresar en la distribución diferencial de lo humano, sus propiedades esenciales, su cuerpo con órganos y sus arquitecturas somáticas (human flesh).

De manera sugerente encontramos a Otto en el matadero, en el espacio social que produce técnicamente carne a partir de los cuerpos, que aísla la carne común (embodied life) en carne comestible y consumible. Otto mastica una presa de pollo crudo mientras los obreros del matadero continúan deshuesando piezas, una y otra vez. Aquel espacio de muerte que es recluido y aislado de otros espacios sociales, se enrarece con la presencia fugaz de Otto, cuya corporalidad es puro hiato, herida expuesta y carne en descomposición.

Esa proximidad que propone la escena entre la carne zombi y la carne animal parecen iluminar aquellas bio(tanato)politicas que, como las industrias agroalimentarias, producen muerte. La producción alimenticia se realiza como economía del asesinato animal y bajo una estructura sacrificial o como lógica del hay que comer al otro, aquello que Derrida (2005) denomina esquema carno-falo-logocéntrico. Se trata del esquema viril y masculino que subyace como modo de ser sujeto y se vincula con la autoridad soberana. Ser sujeto implica, en alguna medida, ese modo incondicional del sí mismo soberano (ipse) sobre todo lo otro y supone una voracidad carnívora. Esto permite pensar el cuerpo de las 
poblaciones animales dedicadas al consumo humano en términos de una administración tecnofarmacológica y biopolítica de la existencia. De nuevo, aqui hay que considerar el esquema de sacrificio animal dentro del nomos moderno por el cual se hace y se preserva la vida a partir de la paradójica - y no por ello menos constitutiva- producción masiva de muerte. Así, siguiendo a Cary Wolfe (2013) debemos decir que en nuestras sociedades normalizadas (o sociedades del postholocausto $o$ de la postdictadura) el acto de la muerte - maquínico, industrial y tecnificado - se ha vuelto tan aceptable como banal, como una cierta matanza del otro viviente que no se considera homicidio. En un sentido ulterior, debemos agregar, la maximización de controles inmunitarios sobre la vida humana no deja de producir asesinatos a escala masiva al tiempo que cuerpos animales son convertidos en un auténtico territorio productor de materias primas farmacológicas, de ensayo clínico y consumo.

No obstante, como señalamos, la ingesta de Otto es, cuanto menos, arbitraria: mastica y engulle pasturas, flores, algún conejo muerto, un gato vivo y finalmente carne animal industrializada $y$, por supuesto, vísceras humanas. Si "el mundo es carne", como afirma Medea, si su materia es carne para ser consumida, entonces la ingesta de Otto es fragmentaria y carente de todo sentido prefigurado. Y, valga la paradoja, Otto es el dueño y señor que puede devorar al otro, pero esto no implica un sojuzgamiento de lo viviente animal para favorecer lo propiamente humano. Más bien el cuerpo herido de Otto devora la carne muerta para alimento sin que esto implique una ganancia vital, un erigirse del yo soberano, un engrandecimiento de su propia vida cualificada sobre la vida sin calificar del animal. Otto devora, come y engulle pero no posee la capacidad para metabolizar, es decir, no se alimenta en los términos normales del circuito producción-consumo-ganancia. De algún modo, Otto se alimenta sin sacrificio alguno. Podríamos afirmar que lo que consume es "humanidad", en tanto su alimentación pareciera derruir la especificidad de la figura del soberano-masculino. En este sentido, el apetito de Otto diluye la centralidad de lo humano y la jerarquía sobre otras formas de lo viviente: consume pasto, animales y humanos, pero a la vez no se alimenta, no dispone ni se apropia de los otros, antes bien hace visible el mecanismo implícito en todo sacrificio de la carne.

El cuerpo muerto de Otto, o más bien el resto corporal, habita una zona de indistinción o de exceso entre lo humano/inhumano, persona/no 
persona, orgánico/inorgánico, cuerpo vivo/cadáver. Esa distinción se vincula con un cálculo biopolítico en sociedades tanatológicas: algunas vidas son protegidas y producidas a costa del abandono, desprotección y exterminio de tantas otras vidas (humanas, animales, zombis, monstruosas, queer, etc.). Estas marcaciones y jerarquías de lo viviente se materializan en la distinción entre flesh y meat. Frente a la conservación del cuerpo cerrado sobre sí mismo que pretende el paradigma inmunitario, la noción de carne como "la modalidad del ser en común" (Esposito, 2009: 172) se propone como soporte presubjetivo, abierto a la herida, al contagio, a lo colectivo. Para el autor, la carne es "el entramado unitario de la diferencia entre los cuerpos, la impertenencia o, mejor, la intrapertenencia, la cual hace que aquello que es diferente no se cierre herméticamente en su interior sino que quede en contacto con su propio afuera" (ibídem: 171). La distinción entre meat y flesh señala, ante la noción de carne como soporte indiferenciado, justamente, que toda carne está siempre marcada y enmarcada por contextos biopolíticos donde se decide su protección o abandono.

En el registro filmico nos encontramos con un solapamiento de cuerpos y carne. En este sentido, podríamos pensar, no existe en la mirada del zombi una diferencia ontológica entre la carne del operario del matadero y la carne que el mismo operario procesa: todo es, potencialmente, cuerpo y carne (communi corpore). Lo que Otto trae a escena es un borramiento - o, cuanto menos, una suspensión- de las fronteras inmunitarias entre flesh y meat, entre bios y zoé, entre meras vidas y formas de vidas cualificadas, entre carne comestible y cuerpo con órganos, o entre vidas precarizadas y vidas protegidas.

De algún modo, las formas de alimentarse de Otto remiten también a su propia práctica sexual zombi. En las escenas de sexo explícito queda una impresión generalizada, cual sedimento perceptivo, en la que la relación sexual y la obtención de alimento se solapan. En otros términos, aquella reminiscencia vampírica (mordedura-sangre-erotismo) retorna a través de la práctica sexual del zombi (despojada ahora de toda connotación elitista y aristócrata). En la película de Bruce LaBruce, mordedura, alimento y deseo sexual se acoplan en un mismo acto que bien podríamos llamar sexualidad caníbal.

\section{SeXualidad CANÍBAL}

\section{Papeles del CEIC}

http://dx.doi.org/10.1387/pceic.17725 
Las escenas de sexo explícito, que por cierto son apenas unas pocas en relación con la categorización de la película como postporno y sus escándalos subsecuentes (fue rechazada en varios circuitos e incluso censurada), terminan reorganizando una determinada economía erótica corporal, término acuñado por el artista holandés Wink van Kempen y que define, en palabras de Annie Sprinkle: "un nuevo género de material sexualmente explícito que es, quizá, visualmente más experimental, político, humorístico y ecléctico que el resto" (1998: 10). De esta forma, el discurso postporno hace referencia a la "inclusión de los códigos de la representación pornográfica en el registro artístico" cuando este problematiza "el estatuto de la imagen sexualmente explicita" (Gatto, 2015: 50).

Si para la heteronorma la impenetrabilidad del ano del varón heterosexual es constitutiva de la subjetividad humana, o del reino de los vivos, ¿cuál es la experiencia sexual y política que se deriva de la sexualidad zombi de Otto? Observada desde este ángulo, la sexopolítica de Otto desplaza la práctica coitopenetrativa organizada sobre el eje pene-vagina. Por tomar un ejemplo: una escena cifrada en los parámetros del postporno nos muestra cómo el zombi Fritz penetra a su partenaire en una herida abierta en el estómago. Es alli donde podemos entrever la politicidad de un orden corporal, erótico y sensitivo que se ha naturalizado. Esto es lo que Paul B. Preciado (2002) denomina "arquitectura corporal", un aparato de producción somático que opera por división y fragmentación del cuerpo: recorta órganos y genera zonas de alta intensidad sensitiva y motriz (visual, táctil, olfativa), reduce la superficie erótica a los órganos sexuales reproductivos y privilegia el pene como único centro mecánico de producción del impulso sexual.

Retomemos la pregunta: ¿cuál es la experiencia sexual y política que se deriva de la sexualidad zombi de Otto? La sexualidad de Otto es una instancia donde se ve la puesta en funcionamiento de la matriz de inteligibilidad heterosexual o marco de reconocimiento que Judith Butler (2002 y 2007) postulara y según la cual la heterosexualidad no es un atributo innato de cada cuerpo recién nacido ${ }^{5}$. Más bien la matriz de inteligibilidad heterosexual es un modelo epistémico que debe reinscribirse a través de operaciones constantes de repetición y de reiteración de presupuestos, serie paradigmática que liga, de modo

\footnotetext{
${ }^{5}$ Ver también De Mauro Rucovsky (2016). 
causal, sexo, género y deseo. Marcada por su constante control del circuito excitación-frustración, la matriz de inteligibilidad heterosexual se reproduce en coreografías sexuales precisas. De esta manera, la totalidad del cuerpo se torna legible e inteligible gracias a la fragmentación o disección de los órganos sexuales. Es más, son estos órganos sexuales los "productores de lo humano porque solo como sexuado un cuerpo tiene sentido" (Flores, 2010: 2). Es por ello que la sexualidad zombi no pertenece del todo a la norma heterosexual de lo humano y su especie y, por lo mismo, rehúsa de sus rituales, prácticas y códigos. De allí que su sexualidad, en similitud con su alimentación caníbal, es puro exceso, desborde y alteración dentro del modelo de "sexualidad (hetero)normal": es oral, anal, paragenital, caníbal, no reproductiva y necrofilica. Y aquí no solo se trata de la cópula genital y del placer sexual ubicados en zonas erógenas: la coreografía sexual del zombi funciona desarreglando un conjunto de presupuestos alrededor de la sexualidad, sus rituales, saberes, políticas y jerarquías anatómicas. Precisamente, no solo su gimnástica sexual es otra, más próxima al canibalismo y al postporno, sino que además su práctica sexual opaca los parámetros de entendimiento de lo humano mismo. El deseo y la identidad sexual que Otto sugiere ponen en jaque los marcos perceptivos de lo humano, puesto que su práctica sexual no solo es no reproductiva y contagiosa, sino que tampoco es humana.

Quizá una de las tesis más potentes de Michel Foucault en el primer volumen de La Historia de la sexualidad (2002) es aquella que propone una explicación para el interés implícito de la modernidad en cuanto a la proliferación de discursos sobre el sexo cuya tarea, sostiene, es justamente "expulsar de la realidad las formas de sexualidad no sometidas a la economía estricta de la reproducción" (ibídem: 48). Foucault no hace otra cosa que señalar la función inmunitaria del interés regulatorio de los discursos sobre el sexo: al tiempo que hacen de este su objeto, clausuran los múltiples devenires posibles de esa producción discursiva. Se trata, dice, de una "incitación regulada" (ibídem: 47). Lo que propone de manera original Otto; or, Up with Dead People es justamente un doble juego entre una nueva política de representación del sexo y la visibilización de los propios aparatos de producción de esa nueva política que implica el postporno. Pone en evidencia así, la aparición de una nueva política de representación del sexo a través de una serie de dispositivos a los que el postporno, tal como lo 
entendemos, viene a contestar. Es decir, la película de LaBruce muestra en paralelo la propia práctica sexual de Otto y aquella que performa como actor en el filme dentro de la película. Lo que queda evidenciado es que su propia práctica es inaprensible, aún por aquellos discursos para los cuales una sexualidad zombi puede ser una figura para pensar políticas de representación de la sexualidad por fuera de los marcos de inteligibilidad de la heteronorma.

Además, en la práctica sexual zombi podemos leer otra manera de contestar a la lógica inmunitaria. Más que la representación de la sexualidad, aquí aparece otra dimensión que refiere a los modos de relacionalidad corporal o las formas en las que inmunitariamente se concibe el límite entre cuerpos. La práctica sexual de Otto pareciera contraria al discurso de la inmunología que concibe el cuerpo y el yo como "una entidad espacial protegida por rígidos límites genéticos y casi identificado con la lucha por defenderlo" (Esposito, 2009: 225). Frente a esta concepción del cuerpo cerrado sobre sí, y en activa lucha por mantener esa frontera entre lo individual y lo común, la práctica sexual de Otto hace de la intrusión y de la penetrabilidad del cuerpo toda una potencia productora de placer sexual. Si el paradigma inmunitario, como señala Alicia Vaggione, hace de "la lógica de la intrusión una amenaza constante y polivalente" (2013: 187), Otto descubre en esa lógica una política sexual invirtiendo su matiz negativo: convierte amenaza en placer y hace del cuerpo una superficie de disolución de las fronteras entre lo individual y lo común, tal como sucede en la escena a la que referimos al comienzo de este apartado.

Es por esto que podemos afirmar que el cuerpo en descomposición de Otto, su materialidad fétida y su sexualidad caníbal, produce una desnaturalización del cuerpo normal y del aparato de producción somático. Además, la arquitectura corporal de los vivos, esto es, las jerarquías genitales y sus coreografías prefiguradas, son alteradas por su práctica sexual. Lo que podríamos llamar una "sexualidad zombi" es entonces una potencia de la supervivencia, el despertar del deseo homoerótico y el reaparecer de lo muerto, lo condenado al abandono, las vidas no potenciables. Cabe señalar una diferencia con el espectro, de especial interés para los debates más recientes de la biopolítica y como figura ejemplar del retorno de lo muerto en la cultura contemporánea: el zombi conserva su corporalidad -siempre putrefacta y en descomposición-, es decir, vuelve de la muerte 
conservando el cuerpo cuya descomposición inminente será un elemento estético central.

La supervivencia del resto corporal zombi ilumina una línea de agenciamiento sexual que mantiene en suspenso la dialéctica entre lo vivo y lo muerto, es decir, su práctica sexual se realiza como una insistencia recurrente: la presencia del zombi vincula la sexualidad de los muertos con la de los vivos y esa es su potencia inmanente -aun muertos y sepultados, los zombis no dejan de producir algún tipo de placer sexual-. Si la muerte se revela como potencia sexual entonces la sexualidad de los vivientes no es un acto de afirmación vital sino que, por la presencia de la sexualidad zombi, sigue el movimiento continuo que la arrastra hacia la muerte. Resuena aquí lo formulado por Bataille respecto de Sade y el hombre normal (2006: 183), donde nos hallamos frente al exceso erótico que vincula la sexualidad con un acto de afirmación soberana y por lo tanto con la necesidad de matar y hacer daño, es decir, con un gasto improductivo y sin mesura. No obstante, otra línea de análisis también puede leerse alrededor de la sexualidad zombi queer y la muerte, justamente aquella que vincula duelo y cultura heteronormativa, donde las pérdidas queer no pueden "admitirse" como vidas que se pierden (Ahmed, 2015: 240). De uno u otro modo, la sexualidad del zombi y su insistencia sobre la vida iluminan una cierta potencia sexual, disidente y queer de los cuerpos muertos o en sentido general: condenados al abandono, muertos, o no reconocibles como cuerpos humanos pero todavía deseantes.

\section{COMUNIDAD DESCOMPUESTA}

El film de Bruce LaBruce es presentado como un documental dual y complementario sobre Otto. Como mencionamos, consta de un subregistro en su interior. Se trata de una película ficcional de bajo presupuesto bajo la dirección de Medea Yarn: Up with Dead People. Medea es quien recluta a Otto y a un conjunto de actores, para filmar una película de cine "porno político zombi". Una vez más, la alegoría al mito clásico es reactualizada, pero esta vez bajo el signo del montaje de imágenes, de tiempos y de ontologías. Anagrama de la cineasta experimental Maya Deren (Bernini, 2017: 116), Medea Yarn es el arquetipo femenino de bruja, lesbiana alternativa y transgresora estética. Una de las figuraciones, por excelencia, de la sustitución e inversión edípica de Occidente: Medea es madre, amante y asesina de su 
propia progenie. Al mismo tiempo, Medea es la encargada de resguardar a los malvivientes zombis de aquellas hordas de justicieros genocidas. Una vez más, aquel viejo sueño de exterminio (Giorgi, 2004) impregna el tejido social de la ciudad. Los zombis son acosados y ajusticiados en nombre de la monstruosidad que encarnan: "Una plaga gay que había descendido sobre la humanidad" (LaBruce, 2008: 00:30:12). Pánico moral y lógica inmunitaria se combinan en los parámetros correctivos de esta (hetero)horda que se encarga de perseguir a todos los muertos vivos. Su tarea consiste en exterminar, valga la paradoja, a los muertos, erradicarlos de manera definitiva (zombidom), en tanto sus cuerpos putrefactos o sus sexualidades son infecciosas y su multiplicación es inminente. Frente a esto, Otto se refugia en Medea. Bajo su protección las vidas zombis son celebradas.

Medea filma y, mientras eso sucede, lo que produce es un programa político transformador. Hacia el desenlace de su proyecto fílmico, el plan emancipatorio de Medea se revela en términos sexuales, una orgía gay zombi que funciona como una proclama: "No hay revolución social sin revolución sexual". Por su parte, Otto deviene actor de sí mismo frente al resto de los actores, convocados por Medea, para hacer de (performar como) zombi. Actuación y reivindicación coinciden en el filme que Medea lleva a cabo, tal como lo indica su discurso:
"Ahora, levanta tu mano fuera de la tumba/ levántala, en forma de protesta en contra de todas las injusticias perpetuadas en contra los de tu tipo. Levántala, en solidaridad con los solitarios y los débiles y los desposeídos de la tierra. Para los que no encajan y los mariquitas y los agotados leídos de la placa. Quienes han sido enterrados y olvidados, por los que no tienen piedad ni corazón (...) de la mayoría fascista. ¡Levántate!" (LaBruce, 2008: 00:53:25-00:54:08)

Frente a la domesticación del zombi y su reflejo conformista, Medea reivindica su inmanente potencialidad sexual y política. Y este doble registro, de un lado la domesticación y del otro la resignificación política del zombi, se ven reflejados en el uso del color: el subregistro de Medea en blanco y negro (al estilo de las películas del cine mudo) y, en paralelo, los periplos de Otto en colores.

Ahora bien, el registro de Medea en Up with Dead People no solo constituye un programa filmico-político sino que también reconstruye una agenda política vinculada al feminismo marxista en tensión con una agenda de la disidencia sexual (que podríamos relacionar con lo gay 
zombi). De uno u otro modo, Otto trae a escena un sujeto emancipatorio que Medea se encarga de anunciar: "Era el hombre vacío, el significado vacío en el que podía proyectar su agenda política" (LaBruce, 2008: 00:23:01). Bajo la proclama revolucionaria de Medea, Otto es el portavoz de una otredad radicalizada y emancipatoria. No obstante, también podríamos pensar el esfuerzo narrativo de Medea desde una "lógica extractivista" (Colectivo Juguetes Perdidos, 2014: 155) o de una "colonización de experiencias" (Radi, 2015; Cabral, 2009) que reproduce un discurso exterior y un conjunto de voces sobre los zombis. Si bien Medea no busca hablar o transcribir la lengua de Otto, la tentación de extraer el plusvalor político de la muerte-vida zombi para transformarlo en capital político que circule en otro ámbito es muy grande.

Mientras que para Medea, Otto y los zombis configuran una potencia política alrededor de la guerrilla zombi, no puede pasar desapercibida la autopercepción de Otto dentro de sus propios términos. Otto es conducido por un deseo de apremio y esto lo lleva al encuentro de otros, de una comunidad de semejantes y parias marginados. Y es aquí donde la comunidad entra en cuestión.

Otto es leído como un gay vestido de zombi y allí mismo, en la puerta de ese antro llamado Flesh, le sugieren no ingresar porque todo el mundo ahí está "muerto", cuestionamiento que plantea cierta ironía: Otto es quien en realidad está muerto respecto de aquellos gays vestidos como zombis y de ello se deriva su impertenencia con el espacio que lo convoca como cliente. Quizá de lo que escapa Otto es de cierta identificación entre comunidad y público -entendido como un grupo de consumidores o nicho de mercado- o bien rehúye a la asimilación de un estilo de vida superficialmente zombi y su respectiva comunidad de pertenencia.

Es alli donde estas interrogaciones apuntan a otro terreno. ¿Cómo se relaciona la presencia de Otto zombi con las mutaciones del capitalismo contemporáneo, donde la integración a través del consumo se transformó en el ritual fundamental para la producción de identidades y subjetividades apaciguadas en su potencial crítico? En un sentido no alegórico el acercamiento de Otto a las distintas formas y vínculos afectivos está signado por la imposibilidad de asimilarse al liberalismo queer (Eng, 2010) y al ethos neoliberal que moldea e interpela a la subcultura gay (Aldana Reyes, 2014). En un contexto histórico signado por las políticas de precariedad, austeridad, ajuste y avanzada de la crisis 
global, distintos organismos e instituciones de financiamiento internacional han incorporado un conjunto de políticas humanitarias, centradas primero en el trabajo de la mujer y luego en políticas LGTBIO friendly. Pasado el consenso de Washington (1989), el capitalismo financiero globalizado ha adoptado una postura activa en contra de la discriminación y la fobia hacia personas a personas LGTBIQ (Rao, 2015). Este discurso igualmente colonialista y fagocitante ha propulsado iniciativas alrededor de un conjunto de reivindicaciones y victorias en materia de derechos sexuales - desde matrimonio igualitario, derechos de adopción, políticas antidiscriminatorias hasta el reconocimiento de las distintas identidades de género-, lo que ha producido un "efecto placebo en la identidad queer" (Aldana Reyes, 2014: 8). Esto que produjo que ciertas comunidades gays y queers se amoldaran al orden del futurismo familiar heterorreproductivo (Edelman, 2004) y su teleología, el culto al dinero, las apariencias y la banalidad del consumo, ha desactivado toda capacidad de crítica antinormativa y política progresista.

En este sentido, Otto permite vislumbrar una línea de fuga -o un cortocircuito melancólico, intermitente, fragmentario e imperceptibleal interior de los flujos de la economía sexopolítica y de las estrategias pintorescas de la mercadotecnia política o del pinkwashing, concepto que remite a la utilización de una agenda de derechos civiles y a la visibilidad LGTBIQ en el contexto bélico y, en particular, en relación con las políticas LGTBIQ friendly del Estado de Israel en relación con la ocupación bélica de Palestina (Ritchie, 2015; Spade, 2015 y 2016). La presencia de zombi en tanto cuerpo muerto entre los vivos encarna así la distancia sexual y afectiva de los cuerpos. Toda individualidad es constantemente interrogada sobre el fondo de una materialidad corporal ni completamente viva ni aún muerta. Y allí reside su valor político, a través de la indeterminación ontológica, es decir, los zombis son criaturas técnicamente muertas entre los heterosexuales vivos pero también dentro de la comunidad gay que se viste como ellos. Ya sean estos actores convocados por Medea o los mismos gays zombis en la disco Flesh, todos ellos son versiones del zombi como ropajes sadomasoquistas que son asimilados o adoptados por homosexuales conformistas, en otros términos, gays vivos que pasan por zombis muertos. En cualquier caso, la adopción de uniformes y vestimentas zombis como estética BDSM (Bondage Discipline Sado \& Masoquism) 
indica una "teatralización de la sexualidad" alrededor de la hipermasculinización fascista y la correspondiente fetichización de los otros (Elliott-Smith, 2014b: 8-10).

En estas coordenadas, Otto es un apátrida, un puto o un paria al interior de los circuitos del liberalismo queer (Eng, 2010) o del homocapitalismo (Rahul, 2015: 1) y la comunidad gay acomodada. Si bien Otto merodea o se aproxima a la subcultura gay masculina o, incluso más, es interpelado por la horda de zombis gays - que Medea reconstruye como un llamado a la insurrección-, el afecto comunitario de Otto está marcado por otro signo, el desorden del alma, la crisis identitaria, la esquizofrenia y la melancolía (Elliott-Smith, 2014b: 5-6). Su estética es otra, su modo afectivo está alterado o signado por el deseo inconcluso; su modo perceptivo es el despojo y el abandono, la enfermedad y el contagio, la patología y el trauma psicológico, pero sobre todo la nostalgia melancólica. Aquí emergen otros tantos interrogantes ¿Qué afecto comunitario es posible esbozar en Otto y su deambular zombi? ¿Qué modulación del afecto es posible experimentar en una comunidad de Ottos? Podemos afirmar que su caminar solitario está marcado por el signo de la tristitia, el mal de la bilis negra o melancolía saturnina. Organizada en torno a la teoría de los cuatro humores propuesta por Hipócrates, la melancolía, tristitia, bilis negra o atra bilis (bilis oscura), denotaba una tristeza en el semblante. La modernidad occidental hizo de la melancolía un territorio de invasión y desembarco, repartidos sus despojos por el pujante campo de la biomedicina y su codificación en palabras como depresión crónica, esquizofrenia, trastorno bipolar y patologías varias (Agamben, 1995).

Una primera impresión pareciera indicar que Otto es quien, con su deambular errante y sin rumbo prefijado, evade toda integración posible: sea con su comunidad de pertenencia - la horda- o sea con la subcultura gay, pujante y acomodada. Al fin de cuentas esta es la característica fundamental del zombi: es casi sin excepción una figura colectiva (Cortés Rocca, 2016: 9-10). O bien Otto es quien no hace comunidad o, como estimamos, lo que hace es volver patente, una vez más, el intrincado problema del orden de la afiliación y el conflicto que es una de las preocupaciones medulares sobre el paradigma inmunitario: ¿cómo vivir juntos?, ¿cómo vivir junto a otros, al lado de otros, junto con otros? 
En este punto vale la pena volver a la noción de inmunidad (como contrapartida de la comunidad) que propone Roberto Esposito. La inmunización vincula a la vida con el poder y es, a la vez, el poder de conservación de la vida (Esposito, 2006: 74). En su semántica, el término remite a la esfera del derecho y a la de la medicina a la vez. Se trata de una protección negativa de un individuo o de un colectivo: para conservar la vida se incorpora aquello que se pretende combatir y por ello es neutralizado o desactivado, i.e., la sexualidad disidente, lo virósico, ajeno, foráneo, lo otro. El dispositivo inmunitario supone, entonces, una reinscripción constante de lo propio y de lo individual sobre lo común, justamente, aquello que se define por su falta de propiedad e indefinición (lo común, el munus). El zombi hace explícito, justamente, el paradigma inmunitario porque, como Otto, este es incorporado al interior de la comunidad gay masculina como un estilo de vida, un ropaje o una estética a consumir. La biopolítica moderna, dice Esposito, tiene dos efectos posibles: produce subjetividad o produce muerte, es política de la vida o sobre la vida (2006: 53). Ahora bien, el zombi pareciera responder a esa lógica para plantear una la potencia subjetiva y comunitaria de esas vidas abandonadas 0 empujadas (inmunitariamente) hacia la muerte. Es esta potencia la que pretende representar Medea Yarn, la de la comunidad zombi, y en este punto es que la mirada de Otto tiene una vigencia sobre la que vale la pena volver, en tanto muestra lo incapturable de esa potencia: es un zombi haciendo el papel de un zombi con el que no termina de identificarse.

En tiempos post-Stonewall o post derechos civiles, el liberalismo queer y el ethos neoliberal hacen de la comunidad gay-queer una marca inmunitaria que tiende a la homogeneización ontológica (no hay alteridad ni otredad posible sino igualación ante el consumo) y al esencialismo sexual (aquellos hombres gays que viven en centros urbanos poseen un numero de afinidades compartidas que se predican de su misma sexualidad). La radicalidad sexual de Otto horada en varios sentidos esta comunidad inmunizada contra los devenires sexogenéricos previstos por el homocapitalismo. Frente a la inmunización que pretende contener la comunidad LGTBIQ y normalizar formas de su reconocibilidad en los parámetros del mercado, la estética hipermasculina y el futuro reproductivo (Edelman, 2004), Otto radicaliza lo común (el munus impropio) desde sus prácticas sexuales alimentarias 
(como vimos, siempre superpuestas), su indeterminación ontológica (Aldana Reyes, 2014: 12), su rareza (queerness) como "otredad radical", su comunidad de extranjeros en soledad-común y su naturaleza todavía marginalizada, enfermiza y melancólica (Elliott-Smith, 2014b: 5).

Pero volvamos sobre la pregunta: ¿cómo vivir juntos? Efectivamente, es posible rastrear otra forma comunitaria en Otto. Lo que el zombi demanda, a través de su caminar errante, no es una mera compañía en particular, sino una variación en el modo de la sociabilidad misma: ¿acaso sea esta una "comunidad de monstruos" (Torrano, 2013)? Valga su paradójica constitución, se trata de una suerte de horda melancólica agrupada alrededor de la soledad -o bien de un suelo de lo común, munus, que resulta ser impropio, carece de todo predicado específico-. Otto logra reconstruir una forma comunitaria a pesar de su espíritu errante y fugaz. Antes que una comunidad de los iguales ante la superficialidad del consumo (incluso, vale aclarar, una comunidad que incorpora y asimila a los zombis como pura actuación, ropaje y mascarada), o de una comunidad fundada en el esencialismo sexual, la comunidad del zombi es delineada desde la singularidad heterogénea del cuerpo muerto y la errancia subjetivante de Otto. Y esa es su potencia afirmativa, una sexopolítica zombi que abre modos de lo común corporal (o del munus por-venir) y que funciona sobre un terreno liminal entre la vida y la muerte. En otros términos, en el contacto y el vínculo entre cuerpos, la individualidad de los zombis melancólicos logra delinear una singularidad de los solitarios, una especificidad del ser zombi disidente a su misma comunidad-horda de pertenencia. De allí que su deambular sin rumbo fijo prefigure una comunidad de solitarios, de melancólicos que rehúsan las marcas identitarias de los todavía vivos y aun de los ya muertos. Comunidad de los solitarios y melancólicos, pero comunidad al fin: antes que vivir juntos, se sugiere en la película, se trata de ser extranjeros juntos. Leido sobre este trasfondo sensible puede entenderse a Otto, de modo anacrónicamente contemporáneo, como una forma de política oposicional al pujante homonacionalismo (Puar, 2007) de comunidades LGTBIQ.

En la escena final de la película, el zombi postidentitario se marcha solitario, haciendo autostop en alguna ruta de la periferia de la urbe, ciudad de los vivos y sus ilusiones que resulta incomprensible para los muertos-vivientes; sin redención posible, se aleja de entre los vivos y sus muertos. Sobre su cabeza vemos un arcoíris ¿Acaso queda alguna 
posibilidad de refundar lo social, los vínculos afectivos, algún espacio para lo común? Algo le indica que al norte el frío reconfortará su carne putrefacta: "Tal vez encuentre más tipos como yo allí arriba y aprenda a disfrutar la compañía. Tal vez un nuevo modo de muerte" (LaBruce, 2008: 01:28:55- 01:29:08)

\section{DeVENIR ZOMBI}

Zombis/ hay zombis/ en los matorrales/ en los puertos/ en los dias que a cada uno le toca por vivir/ y la escritura en marcha automática es/ zombi/ hay zombis/ en los matorrales/ en el capital financiero/ en las homofonias/ en las cacofonias/ en las sinestesias en el correlato objetivo en la metáfora como continuación de la dominación de la producción y el consumo por otros medios/ hay zombis

Javier M. Ramacciotti, El yo es lo más importante

La puesta en escena del muerto viviente que presenta Bruce LaBruce expande la serie de problematizaciones bio(tanato)políticas que comenzamos a delinear, pero volcadas hacia una reflexión sobre la sexualidad y la comunidad a través de las políticas de muerte como hilo conductor para cuestionar y repensar las políticas de subjetividad, así como también las formas de interacción entre el cuerpo individual y la comunidad.

En este punto quizá sea necesario reconsiderar la noción de tanatopolítica para pensar las políticas de subjetividad que Otto configura con su andar y devorar errante. La película que analizamos nos permite atravesar capas temporales superpuestas $y$, a través del contagio y del canibalismo, imaginar una comunidad posible entre vivos y muertos, cuerpos y cosas condenados al residuo que reclaman vigencia; una sexualidad no antropocéntrica y, más aun, una sexualidad cuyo centro pase por devorar "lo humano" su gestión de las arquitecturas corporales y jerarquías - 0 , al menos, cuestionarlo-); y por último, funciona como imaginario alternativo frente a una norma identitaria que presupone lo colectivo y lo común como totalidad homogénea. Es alli donde la película de LaBruce imagina la potencia de una comunidad desde el cuerpo y la singularidad, pero no como cuerpo inmunizado, sino justamente como un desafío a las fronteras del cuerpo

\footnotetext{
${ }^{6}$ Javier Martínez Ramacciotti propone una reescritura en clave zombi del poema de Néstor Perlongher que sirve de epígrafe al comienzo de estas páginas.
} 
propio y del cuerpo común (o lo precario-vulnerable) que cuestione la pretensión neoliberal de identificar comunidad con público o nicho de mercado. En este sentido, Donna Haraway señala:

\begin{abstract}
"el sistema inmunitario es un mapa diseñado para servir de guía en el reconocimiento y en la confusión del yo y del otro en la dialéctica de la biopolítica occidental, es decir, es un plan de acción para construir y mantener las fronteras de lo que se entiende por el 'yo' y por 'el otro' en el importante terreno de lo normal y lo patológico" (1995: 350)
\end{abstract}

Otto es quien desafía una y otra vez esas fronteras poniendo en crisis las categorías disponibles para pensar a los sujetos, lo patológico, la propia distinción entre el yo y el otro, las diferencias entre sujetos y objetos, entre vivos y muertos. Luego del deambular zombi queda expuesta la potencia de la performance de Otto para quien nada es inmune a su apetito sexual.

En primer lugar, Otto pone sobre la mesa de manera explícita y novedosa la pregunta por los modos en los que la biopolítica contemporánea separa y clasifica cuerpos y cosas a ser protegidas o desechadas. En torno a la carne - que recorrimos en la distinción entre los términos de la lengua inglesa flesh y meat- y la distinción bio(tanato)política entre la carne a consumir y la carne a proteger (la carne del trabajador, la carne de la comunidad LGTBIQ, la carne del cadáver de un animal arrojado en un basural, la carne muerto viviente) la película descubre y pone en cuestión todo un aparato clasificatorio inmunitario, destinado a repartir violencias sobre ciertos cuerpos en favor de la potenciación de otros. Otto recorre espacios destinados al desecho, a los restos, a la muerte: transitar errante desde su propia tumba, el basural, montañas de autos abandonados o el frigorífico. Y a partir de estos escenarios expone lo común en esa materia condenada al abandono. De este modo, la película sugiere el fundamento, a la vez evidente y oculto, de los modos en que la cultura reparte protección y abandono sobre los cuerpos.

En segundo lugar, la película tiene el mérito de hacer gravitar toda una serie de interrogantes en torno a la sexualidad y a la identidad: a los modos en cómo la cultura hace pasar a través de esos dos vectores el fundamento de ese reparto. Es decir, expone de qué modo en la inteligibilidad se juega la protección o abandono en el reparto de violencias y derechos. Y muestra aun cómo las matrices para esa 
reconocibilidad están configuradas por políticas de representación específicas con sus propias reglas, por tomar un caso paradigmático, como Estado-nación configura normas identitarias de lo colectivo (¿quiénes son legibles y representables, acaso los cuerpos de inmigrantes desplazados y refugiados, homosexuales-queers, contagiosos y enfermos, zombis e ilegales?). Matrices de reconocibilidad que siempre se hallan configuradas por el mercado y sus flujos de circulación -aun en sus márgenes: el postporno-. A través del postporno y de la propia producción de formas alternativas de regímenes de representación de la sexualidad LGTBIQ y con el zombi como figura de la alteridad contagiosa, la película de LaBruce hace explícita también la relación entre sexualidad y política. Y desde allí pareciera sostener que cualquier tipo de desplazamiento $o$ cuestionamiento de las matrices disponibles debería seguir pasando por la sexualidad como performance. Esto es, sostiene, aun en los márgenes difusos entre la vida y la muerte, una sexopolítica zombi como potencia afirmativa que necesariamente parte del cuerpo inacabado y foráneo, no cicatrizado e infeccioso, su carne expuesta y necesariamente vulnerable.

\section{BIBLIOGRAFÍA}

Agamben, G. (1995). Estancias. La palabra y el fantasma en la cultura occidental. Valencia: Pre-textos.

Agamben, G. (2010). Signatura rerum. Sobre el método. Barcelona: Anagrama.

Ahmed, S. (2015). La política cultural de las emociones. Ciudad de México: UNAM.

Aldana Reyes, X. (2014). Beyond the metaphor: gay zombies and the challenge to homonormativity. Journal for Cultural and Religious Theory, 13(22), 1-12.

Bataille, G. (2006). El erotismo. Buenos Aires: Tusquets.

Bernini, L. (2017). Queer Apocalypses: Elements of anthysocial theory. Basingtoke: Palgrave Macmillan.

Butler, J. (1989). Imitation and Gender Insubordination. Conferencia on Homosexuality en la Universidad de Yale. The Lesbian and gay studies reader. Nueva York: Routledge. 
Butler, J. (1990). Gender Trouble. Feminism and the Subversion of Identity. Nueva York-Londres: Routledge.

Butler, J. (2002). Cuerpos que importan: sobre los limites materiales y discursivos del "sexo". Buenos Aires: Paidós.

Butler, J. (2007). El género en disputa: El feminismo y la subversión de la identidad. Barcelona: Paidós.

Cabral, M. (2009). Salvar las distancias. Apuntes acerca de biopoliticas del género. En B. Preciado et al. Conversaciones feministas. Biopolítica (123-138). Buenos Aires: Ají de pollo.

Cohen, J. (2012). Undead (A Zombie Oriented Ontology). Journal of the Fantastic in the Arts, 23(3), 397- 412.

Colectivo Juguetes Perdidos (2014). ¿Quién lleva la gorra? Violencia, nuevos barrios, pibes silvestres. Buenos Aires: Tinta Limón.

Cortés Rocca, P. (2009). Etnología ficcional. Brujos, zombis y otros cuentos caribeños. Revista Iberoamericana, LXXV(227), 333-347.

Cortés Rocca, P. (2016). Vidas perdurables. Bioy Casares, visualidad, afectos y fantasmas. En B. Keizman y C. Vergara. (Eds.). Profundidad de campo. Des-encuentros cine-literatura en Latinoamérica (131-147). Santiago de Chile: Metales pesados.

De Mauro Rucovsky, M. (2016). Cuerpos en escena. Materialidad y cuerpos sexuado en Judith Butler y Paul B. Preciado. Madrid: Egales.

Derrida, J. (2005). Hay que comer o el cálculo del sujeto. Confines, 17, 1-23

Edelman, L. (2004). No Future: Queer Theory and the Death Drive. LondresDurham: Duke University Press.

Elliott-Smith, D. (2014a). Death is the new pornography: Gay Zombies, "Homonormativity and Consuming Masculinity in Queer Horror". En L. Hunt, Sh. Lockyer y M. Williamson (Eds.). Secreening The Undead: Vampires and Zombies in film and television (pp. 148-172). Nueva York: I. B. Tauris \& Co Ltd.

Elliott-Smith, D. (2014b). Gay Zombies: Consuming Masculinity and Community in Bruce LaBruce's Otto; or, Up With Dead People (2008) and LA Zombie (2010). En S. McGlotten y S. Jones (Eds). Zombies and Sexuality: Essays on Desire and the Living Dead (pp. 140-158). Carolina del Norte: McFarland.

Embry, K., y Lauro, S. J. (2008). A Zombie Manifesto: The Nonhuman Condition in the Era of Advanced Capitalism. Boundary, 2, 85-108.

Eng, D. L. (2010). The Feeling of Kinship: Queer Liberalism and the Racialization of Intimacy. Durham: Duke University Press 
Esposito, R. (2006). Bios. Biopolítica y filosofía. Buenos Aires: Amorrortu.

Esposito, R. (2009). Immunitas. Protección y negación de la vida. Buenos Aires: Amorrortu.

Flores, V. (2010). Desorganizar el cuerpo hetero: prácticas de saber/coger como experiencia política. Texto presentado en las $X$ Jornadas Nacionales de Historia de las Mujeres. Universidad Nacional de Luján, 16 al 18 de septiembre. Recuperado de: http://escritoshereticos.blogspot.com.uy/2010/10/desorganizarel-cuerpo-hetero-practicas.html.

Foucault, M. (2002). Historia de la sexualidad. Vol. 1. La voluntad de saber. Buenos Aires: Siglo XXI.

Foucault, M. (2010). Defender la sociedad, Curso en el Collège de France 1975-1976. Buenos Aires: Fondo de Cultura Económica.

Gatto, F. G. (2015). Pospornografías. Ciudad de México: La Cifra Editora.

Giorgi, G. (2004). Sueños de exterminio. Homosexualidad y representación en la literatura argentina contemporánea. Rosario: Beatriz Viterbo.

Halberstam, J. (2011). The Queer Art of Failure. Durham: Duke University Press.

Haraway, D. (1995). La biopolítica de los cuerpos posmodernos: construcciones del yo en el discurso del sistema inmunitario. En Ciencia, cyborgs y mujeres. La reinvención de la naturaleza (pp. 247395). Madrid: Cátedra.

Hribal, J. (2014). Los animales son parte de la clase trabajadora y otros ensayos. Madrid: ochodoscuatro ediciones.

Grizzell, T. (2014). Re-Animatig the Social Order. Zombies and Queer Failure. En Sh. McGlotten y S. Jones (Eds.). Zombies and Sexuality: essays on Desire and the Living Dead (pp. 123-139). Carolina del Norte: Mc Farland \& Company.

Platzeck, J. (2015). El monstruo y el biopoder. Una lectura biopolítica del zombie (Trabajo final de licenciatura en letras modernas inédita). Universidad Nacional de Córdoba, Córdoba, Argentina.

Puar, J. K (2007). Terrorist Assemblages: Homonationalism in Queer Times. Durham: Duke University Press.

Preciado, P. B. (2002). Manifiesto contra-sexual. Prácticas subversivas de identidad sexual. Madrid: Opera prima.

Radi, B. (2015). Defundamentos y postfundaciones. Revoluciones conservadoras y tecnologías de apropiación de subjetividades 
trans en la obra de Beatriz Preciado. Sexualidad, salud y sociedad. Revista Latinoamericana. CLAM, 20, 1-27.

Rao, R. (2015). Global Homocapitalism. Radical Philosophy, RP, 194, NovDic, 38-49.

Ritchie, J. (2015). Pinkwashing, Homonationalism, and Israel-Palestine: The Conceits of Queer Theory and the Politics of the Ordinary. Antipode, 47(3), 616-634.

Spade, D. (2015). Pinkwashing Exposed: Seattle Fights Back! Documental. Recuperado de: https://pinkwashingexposed.net/.

Spade, D. (2016). Creating Change: Pinkwashing ICE, Pinkwashing Israel. Recuperado de: http://www.deanspade.net/2016/01/15/creatingchange-pinkwashing-ice-pinkwashing-israel/.

Sprinkle, A. (1998). Post-Porn Modernist. My 25 Years as a Multimedia Whore. San Francisco: CleisPress.

Torrano, A. (2013). El monstruo político en las sociedades de control: una consideración ontológica de la monstruosidad (Tesis doctoral inédita). Universidad Nacional de Córdoba, Córdoba, Argentina.

Vaggione, A. (2013). Literatura/enfermedad. Escrituras sobre el sida en América Latina. Córdoba: Editorial de Centro de Estudios Avanzados-Universidad Nacional de Córdoba.

Wolfe, C. (2013). Before the law. Humans and other animals in a biopolitical frame. Chicago: Chicago University Press. 